\title{
Combination Therapy Against Breast Cancer Cells by Docetaxel With Rosmarinic and Thymoquinone: An Experimental Study
}

\author{
Ebrahim Afkhami Saray $^{\mathbb{D}}$, Sodeif Azadmard-Damirchi ${ }^{*}{ }^{\circledR}$, Mahdi Gharekhani ${ }^{1}$
}

\begin{abstract}
Objectives: Combination therapy with powerful and new components is presented as an effective method in treating breast cancer against conventional approaches. Here, we tried to evaluate the implementation of rosmarinic and thymoquinone on the tumor growth inhibition and apoptotic induction of docetaxel on MDA-MB231 breast cancer cells.

Materials and Methods: The drug interaction between rosmarinic acid, thymoquinone, and docetaxel, as the chemotherapeutic drug, was analyzed using the Chou-Talalay method along with CompuSyn. To understand the number of cell proliferation of MDAMB231 breast cancer, a tetrazolium-based colorimetric assay (MTT assay) was investigated. DAPI and the flowcytometric assay were harnessed to evaluate the morphology and the percentage of apoptosis, respectively. Real-time polymerase chain reaction (PCR) was used to recognize the association between the NF- $\mathrm{kB}$ pathway and program cell death signal.

Results: The IC50 values for docetaxel, rosmarinic, and Thymoquinone were $2.6 \pm 0.62 \mathrm{nM}, 15.6 \pm 2.4 \mu \mathrm{M}$, and $35.5 \pm 3.4 \mu \mathrm{M}$, respectively. MDA-MB231 breast cancer showed combination index value following three combination recipes; rosmarinic acid + docetaxel, thymoquinone + docetaxel, rosmarinic acid + thymoquinone + docetaxel was $0.26,0.55$, and 0.08 , which designated a remarkable synergistic effect. The cultivation of the tumor cells under the exposition of docetaxel and rosmarinic, as well as thymoquinone, discovered a substantial upsurge in the anti-proliferative manner of docetaxel from $60 \%$ to $82 \%$, along with a double-fold surge in the number of dead cells. mRNA levels exhibited a noticeable decline in I $\mathrm{kB}-\alpha$ as an indicator of NF- $\mathrm{kB}$ activation and the decline of survivin and Bcl-2 escorted by a surge in pro-apoptotic Bad mRNA levels $(P<0.05)$.

Conclusions: By considering our results, the co-administration of docetaxel, rosmarinic, and thymoquinone can be figured out as a promising adjuvant therapy besides other treatment protocols.

Keywords: Breast neoplasms, Cytotoxicity, Apoptosis, Docetaxel
\end{abstract}

\section{Introduction}

Breast cancer has been categorized as one of the most contributors to causes of cancer death among women in the world due to different reasons such as metastasis, invasion, resistance to conventional chemotherapeutic drugs, and high mortality (1). Taxane-based chemotherapy drugs are frequently used as chemotherapeutic treatments for malignant breast cancer (2). Docetaxel has demonstrated substantial activity as a front-line and second-line chemotherapy regiment in advanced breast cancer patients exposed under anthracyclines drug (3), displaying its toxicity by changing the dynamics of tubulin development in cancer cell lines (4). Even though docetaxel is a powerful and competent chemo drug that can suppress its molecular target. The optimum effectiveness of this drug is confined because this drug is unable to overwhelm the survival signals, which give rise to chemotherapeutic resistance as well as tumor recurrence (5). Chemosensitization, the use of a second agent to increase the susceptibility of the chemotherapy agent, is one promising approach to overcome the drug resistance problem (6).
This compound can competently downregulate the apoptosis signals and act as a chemosensitizer in order to augment chemotherapy agent's efficiency.

There are a number of safe and potent phytochemicals which could have strong anti-cancer properties so much so can act as strong modulator and chemosensitizers when co-administrate with first line anti-cancer agents (7). Rosmarinic acid has been described as one of the potent and powerful polyphenolic compounds extracted from rosemary (Rosmarinus officinalis). This compound has unique and exclusive biological features such as an antimicrobial, antifungal, antioxidant, anti-tumor, and chemoprotective agent (8-10). Thymoquinone is one of major phytochemical usually found in black seed (Nigella sativa) in which has used as medicinal herb (11). Thymoquinone applied as antimicrobial, antidiabetic, antihypertensive and anti-cancer for long time. In cancer investigation, thymoquinone demonstrates favorable activity in cell and animal models and it show antipropagation effect for lung, colon, larynx, ovary and breast cancer cells (12). 


\section{Key Messages}

- Combining treatment with powerful and new components is presented as an effective method in treating breast cancer against conventional approaches.

- The combination of docetaxel, rosmarinic, and thymoquinone can be figured out as a promising adjuvant therapy against breast tumor cells.

The combination of chemotherapeutic drugs with phytochemicals has significantly developed in recent years. Some studies have revealed hopeful results and outcomes (13). This is done to diminish the chemotherapeutic resistance along with conventional chemotherapeutic drugs or to reduce cytotoxicity of chemotherapy toward normal tissues (14). Indeed, combinational chemotherapy may also give a strong sensitization effect on cancer cells, giving them predisposed to apoptosis triggered by various anti-cancer drugs $(15,16)$. The most important molecular mechanism for the effectiveness of chemo-preventive agents is triggered program cell death (17). Thymoquinone and rosmarinic acid seemingly triggers programmed cell death in cancer cells by inhibiting NF- $\mathrm{KB}$ activation and prohibition of $\mathrm{Nrf} 2$ and tumour necrosis factor $\alpha$ associated with-induced NF- $\mathrm{kB}$ activation, respectively, and also decrease Bcl-2 anti-apoptotic protein (18). This study evaluated the effect of rosmarinic acid and thymoquinone in combination with docetaxel on cell viability and apoptosis induction. Also, we explored the mechanisms underlying the potential ability of rosmarinic acid and thymoquinone to decrease the cell-cytotoxicity effect of docetaxel.

\section{Materials and Methods}

Anti-proliferation Assay

The cancer cells were cultured under the standard circumstance. MDA-MB231 cells were cultured in 6000 per well and exposed under 1-16 nmol/L of docetaxel, 5-80 $\mu \mathrm{mol} / \mathrm{L}$ of rosmarinic acid, and 10-160 $\mu \mathrm{mol} / \mathrm{L}$ of thymoquinone for 24 and 48 hours. After the aforementioned time, a $200 \mu \mathrm{L}$ new solution of RPMI-1640 medium which contained $2 \mathrm{mg} / \mathrm{mL}$ of MTT, was substituted with the previous medium. Then, the plate was incubated for 3-4 hours at the standard situation. Subsequently, media including MTT solution was unloaded, and DMSO was harnessed to solubilize formazan crystals (19).

Analysis of Drug Interaction Using the Combination Index

The drug interaction between rosmarinic acid, thymoquinone, and docetaxel as a chemotherapeutic drug was analyzed using the Chou-Talalay method (20). MTT assay was accomplished in 96-well plates. Rosmarinic acid and thymoquinone were applied at a constant concentration (rosmarinic acid $10 \mu \mathrm{M}$ and thymoquinone
$20 \mu \mathrm{M})$. While, docetaxel as a therapeutic agent was used at a different concentration $(1,2,3$, and $5 \mathrm{nM})$ to resolve whether the effects comply with the dose-dependent pattern.

\section{Monitoring Apoptotic Manner of Adjuvants}

Annexin V/PI double staining was done to measure the amount of cell population that undergo apoptosis in response to the drug treatment with respect to the manufacturer's instruction. Approximately $25 \times 10^{4}$ cell/ well were inoculated in seeding plates and exposed with $10 \mu \mathrm{M}$ rosmarinic acid, $20 \mu \mathrm{M}$ thymoquinone, and $2 \mathrm{nM}$ docetaxel in single and combined condition. After 24 hours, the cell was harvested and washed with phosphate-buffered saline (PBS), resuspended in binding buffer, and kept in the dark for 15 minutes to stain with flowcytometric dye.

The Investigation of Apoptotic Nuclei

DAPI (4',6-diamidino-2-phenylindole) staining was carried out following an established protocol beforehand (21). In continue, cells were incubated with rosmarinic acid $10 \mu \mathrm{M}$, thymoquinone $20 \mu \mathrm{M}$, docetaxel $2 \mathrm{nM}$, and a combination of two or three agents for 48 hours with the indicated drugs. To increase the penetration of cancer cells to DAPI dye, Triton X-100 was harnessed and allowed cancer cells to be fixed with paraformaldehyde for $18 \mathrm{~min}$. The decomposition of cells was recognized applying a fluorescence microscope with a $40 \mathrm{X}$ objective lens.

\section{Following Gene Expression Pattern}

The MDA-MB231 cell lines $3 \times 10^{5} /$ well were exposed with rosmarinic acid $10 \mu \mathrm{M}$, thymoquinone $20 \mu \mathrm{M}$, docetaxel 2nM, and their combination. After 24 hours, Total RNA was extracted from MDA-MB231 cells applying phase separation method according to the manufacturer's established protocol by the manufacturer (22). The total RNA quantity was measured using Nanodrop. The yield of cDNA synthesis by applying the First-Strand cDNA Synthesis kit according to the constructer's guideline. Real time-PCR was accomplished by applying the SYBR Green Master Mix and run-on ABI 7000 real-time polymerase chain reaction (PCR) (USA). The primer sequences used for each gene are available in Table 1.

\section{Statistical Analysis}

Graph Pad version 8.3 Software (San Diego, CA, USA) was to analyze the data submitted as mean $\pm \mathrm{SD}$. The $\mathrm{IC}_{50}$ value was calculated using nonlinear regression analysis. The $P$ value $<0.05$ was considered statistically significant.

\section{Results}

Anti-proliferative Characteristic of Docetaxel, Rosmarinic Acid and Thymoquinone in MDA-MB231 Cell Line Anti-cytotoxic properties of docetaxel, rosmarinic acid, and thymoquinone were assessed by cell cytotoxicity MTT 


\begin{tabular}{|c|c|}
\hline Objective Genes & Primer Sequence \\
\hline \multirow{2}{*}{ ІкB- $\alpha$} & Forward: 5'-GCTGAAGAAGGAGCGGCTACT-3' \\
\hline & Reverse: 5' -TCGTACTCCTCGTCTTTCATGGA-3' \\
\hline \multirow{2}{*}{ Bad } & Forward: 5'- GGAAGACGCTAGTGCTACAGA-3' \\
\hline & Reverse:5 '- GAGCCTCCTTTGCCCAAGTTT-3' \\
\hline \multirow{2}{*}{$\mathrm{Bcl}-2$} & Forward: 5' - GGCTGGGGATGACTTCTCTC-3' \\
\hline & Reverse: 5' - ACAATCCTCCСССАGTTCAC- 3' \\
\hline \multirow{2}{*}{ Survivin } & Forward: 5'- CAAGGACCACCGCATCTCTAC-3' \\
\hline & Reverse: 5'- AGTCTGGCTCGTTCTCAGTGG-3' \\
\hline \multirow{2}{*}{$\beta$-Actin } & Forward: 5'- CACCATTGGCAATGAGCGGTTC-3' \\
\hline & Reverse: 5' - AGGTCTTTGCGGATGTCCACGT-3' \\
\hline
\end{tabular}

assay applying MDA-MB231 cells. The current cells were exposed with the desired concentration of docetaxel ( 1 to $16 \mathrm{nM})$ and rosmarinic acid $(5-80 \mu \mathrm{M})$, and thymoquinone (10 to $160 \mu \mathrm{M}$ ) for 24 and 48 hours (Figure 1). Docetaxel, rosmarinic acid, and thymoquinone revealed the characteristic sigmoidal dose-dependent cytotoxicity on MDA-MB231 cells. Docetaxel, rosmarinic acid, and thymoquinone powerfully repressed the proliferation of MDA-MB231 cells with the IC50 of $2.6 \pm 0.62 \mathrm{nM}, 15.6 \pm$ $2.4 \mu \mathrm{M}$, and $35.5 \pm 3.4 \mu \mathrm{M}$, respectively. Intensification in the amount of anti-cytotoxic manner was dependable on increasing the treatment time and dosage of the component (Table 2). The MDA-MB231 cells were exposed under rosmarinic acid $(10 \mu \mathrm{M})$, thymoquinone $(20 \mu \mathrm{M})$, and docetaxel $(1,2,3$, and $5 \mathrm{nM})$ for 24 hours. Rosmarinic acid and thymoquinone co-administration with docetaxel as main chemotherapy drug exhibited a noteworthy upsurge inefficiency of docetaxel in anti-proliferative properties, which increased the percent of inhibitory effect for rosmarinic acid + docetaxel, thymoquinone + docetaxel, and thymoquinone + rosmarinic acid + docetaxel $70 \pm 2.4 \%, 65 \pm 1.9 \%$, and $82 \pm 2.6 \%$, respectively $(P<0.05)$ (Figure 2A). This approach relies on the median affect perception. Our findings from combination index plots and values demonstrate a strong synergism between two agents (Figure 2B, C, and D) (Table 3). For example, a mixture of $2 \mathrm{nM}$ docetaxel with $10 \mu \mathrm{M}$ of rosmarinic acid delineated a combination index of 0.26 for cancer cells, which epitomizes a potent synergism.

Combinational Effect of Rosmarinic Acid, Thymoquinone, and Docetaxel on Percentage of Apoptotic Cell Population The enhanced effect of rosmarinic acid and thymoquinone with docetaxel was evaluated by the flowcytometric dye in MDA-MB231 cells (Figure 3). Furthermore, flow cytometry recognized that treatment with rosmarinic acid, thymoquinone, and docetaxel give rise to an outstanding increase in the percent of apoptotic cell population compared with each drug alone. For example, docetaxel alone amplified total apoptotic cells up to $29.4 \%$, while in co-administration percentage of early phase augmented from $29.4 \%$ to $34.6 \%$.
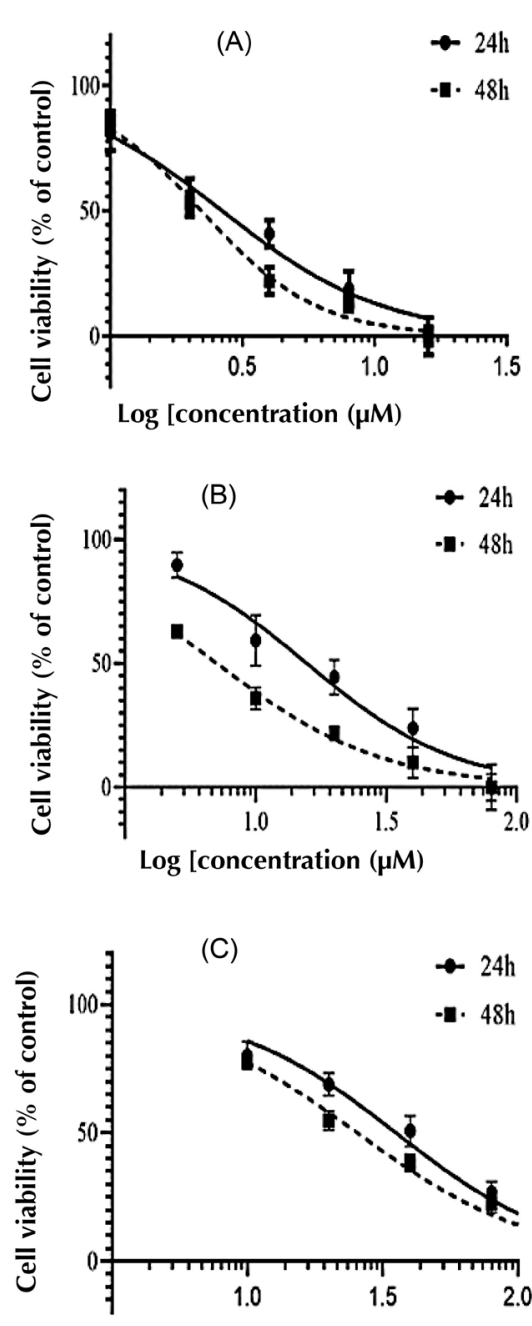

$\log$ [concentration $(\mu \mathrm{M})$

Figure 1. Anti-cytotoxic Manner of Docetaxel, Rosmarinic Acid and Thymoquinone in MDA-MB231 cells. (A) Cells were Exposed with Ascending Dosage of Docetaxel (1-16 nM), (B) Rosmarinic Acid (10-80 $\mu \mathrm{M})$ and $(\mathrm{C})$ Thymoquinone (10-160 $\mu \mathrm{M})$ for 24 and $48 \mathrm{~h}$.

The Role of Successive Therapy of Docetaxel and Rosmarinic Acid and Thymoquinone on Apoptosis Rate To more differentiate the amount of apoptosis by docetaxel, rosmarinic acid, and thymoquinone, we assessed the morphology of nuclei in the apoptotic cells, which was described with a compressed globular to contracted or the nuclei were segmented. Co-treatment with rosmarinic acid, thymoquinone, and docetaxel augmented the percent of under apoptotic cells from $17 \% \pm 2.46$ in a

Table 2. IC Values of Rosmarinic, Thymoquinone and Docetaxel in MDAMB231 Cells

\begin{tabular}{lcc}
\hline Agents & Incubation time(h) & IC $_{50}$ value \\
\hline Rosmarinic $(\mu \mathrm{M})$ & 24 & $15.6 \pm 2.4$ \\
& 48 & $7.09 \pm 2.1$ \\
Thymoquinone $(\mu \mathrm{M})$ & 24 & $35.5 \pm 3.4$ \\
& 48 & $25.5 \pm 3.8$ \\
Docetaxel $(\mathrm{nM})$ & 24 & $2.6 \pm 0.62$ \\
& 48 & $2.2 \pm 0.28$ \\
\hline
\end{tabular}


A

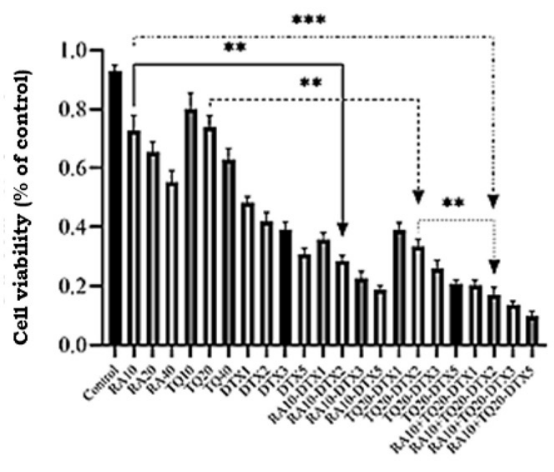

RA \& TQ combination with DTX

B
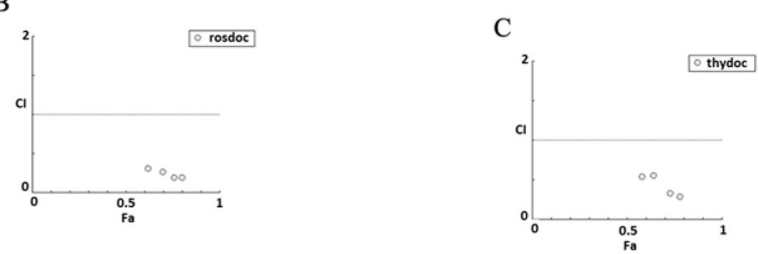

D

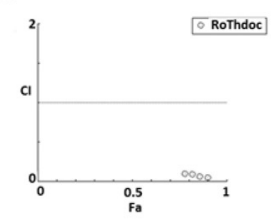

Figure 2. Co-treatment of Rosmarinic Acid, Thymoquinone and Docetaxel on the Blockage Percentage of MDA-MB231 Cell. (A) MDA-MB231 cells were incubated with increasing doses of docetaxel $(1,2,3 \& 5 \mathrm{nM})$, Rosmarinic acid and thymoquinone $(10,20 \& 40 \mu \mathrm{M})$ or a combination of the two reagents (RA10 $\mu \mathrm{M}$-DTX1 nM, RA10 $\mu \mathrm{M}$-DTX2 nM, RA10 $\mu$ M-DTX3 nM and RA10 $\mu$ M-DTX5 nM) for 24 h. (B, C, and D). Combination index values $<1$ designate synergistic effect $\left({ }^{* *} P<0.01,{ }^{* * *} P<0.001\right)$.

single treatment with rosmarinic acid and thymoquinone to about $63 \% \pm 3.62$ in double and triple combinational therapy in MDA-MB231 cells (Figure 4).

The Combinational Effect of Rosmarinic Acid, Thymoquinone, and Docetaxel on the mRNA Level of Apoptotic Signaling Pathway Genes

The key anti-apoptotic and pro-apoptotic genes intricate in the initiation of apoptosis procedure were inspected after combinational treatment of rosmarinic acid (10 $\mu \mathrm{M})$, thymoquinone $(20 \mu \mathrm{M})$ and docetaxel (2 nM). Our findings displayed that the co-administration profoundly lessened the mRNA expression of I $\kappa \mathrm{B}-\alpha, \mathrm{Bcl}-$ 2 , and survivin (Figure 5). Indeed, following exposure with rosmarinic acid \& thymoquinone and docetaxel individual and in concurrent treatment, Bad expression was raised. Our data verified that rosmarinic acid and thymoquinone could dysregulate the expression of the fundamental apoptosis-related genes.

\section{Discussion}

Docetaxel is the most regularly used as the antimicrotubular agent effective in treating patients with breast cancer (23). Presently, in most clinical protocols, simultaneous consumption of two or three drugs with different functions is applied. Combining treatment with adjuvants can intensify the proficiency of main therapeutic drugs, diminish drug-associated toxicity in the host cells, and lessen or reverse drug resistance to chemotherapeutic agents (24). Occasionally combinational chemotherapy is applied not to treat but to decrease symptoms and lengthen life span. Combination drug therapy can be beneficial for patient with advanced cancers that are not appropriate for surgical treatment or radiation therapy (25). Recent studies established that rosmarinic acid and thymoquinone can surges the anti-tumor and antiproliferative behavior of docetaxel in human MDAMB231 breast cancer cell line that show constitutively dynamic NF- $\kappa B(8,11,15)$. To recognize synergism effect of rosmarinic acid and thymoquinone with docetaxel, anti-proliferative manner of aforementioned component was measured by utilizing the isobologram plot (Figure 2). For example, co-treatment of $2 \mathrm{nM}$ docetaxel with $10 \mu \mathrm{M}$ rosmarinic acid exhibited a combination index of 0.27 in MDA-MB231 cells that show powerful synergistic effect.

The fundamental expression of NF- $\kappa \mathrm{B}$ has been demonstrated in numerous malignant cancer (26). Findings also have verified that NF- $\mathrm{BB}$ signaling is a significant and central mechanism for chemotherapy resistance, and

Table 3. Combination Index and Growth Inhibitory Effects of Rosmarinic, Thymoquinone, and Docetaxel MDA-MB231 Cell

\begin{tabular}{|c|c|c|c|c|}
\hline Dose RA $(\mu \mathrm{M})$ & Dose TQ $(\mu \mathrm{M})$ & Dose DTX (nM) & Inhibitory Effect \% & Combination Index \\
\hline 10 & - & 1 & 62 & 0.3 \\
\hline 10 & - & 2 & 70 & 0.26 \\
\hline 10 & - & 3 & 76 & 0.19 \\
\hline 10 & - & 5 & 80 & 0.19 \\
\hline- & 20 & 1 & 58 & 0.53 \\
\hline - & 20 & 2 & 64 & 0.55 \\
\hline- & 20 & 3 & 73 & 0.32 \\
\hline- & 20 & 5 & 78 & 0.28 \\
\hline 10 & 20 & 1 & 78 & 0.09 \\
\hline 10 & 20 & 2 & 82 & 0.08 \\
\hline 10 & 20 & 3 & 86 & 0.06 \\
\hline 10 & 20 & 5 & 90 & 0.04 \\
\hline
\end{tabular}




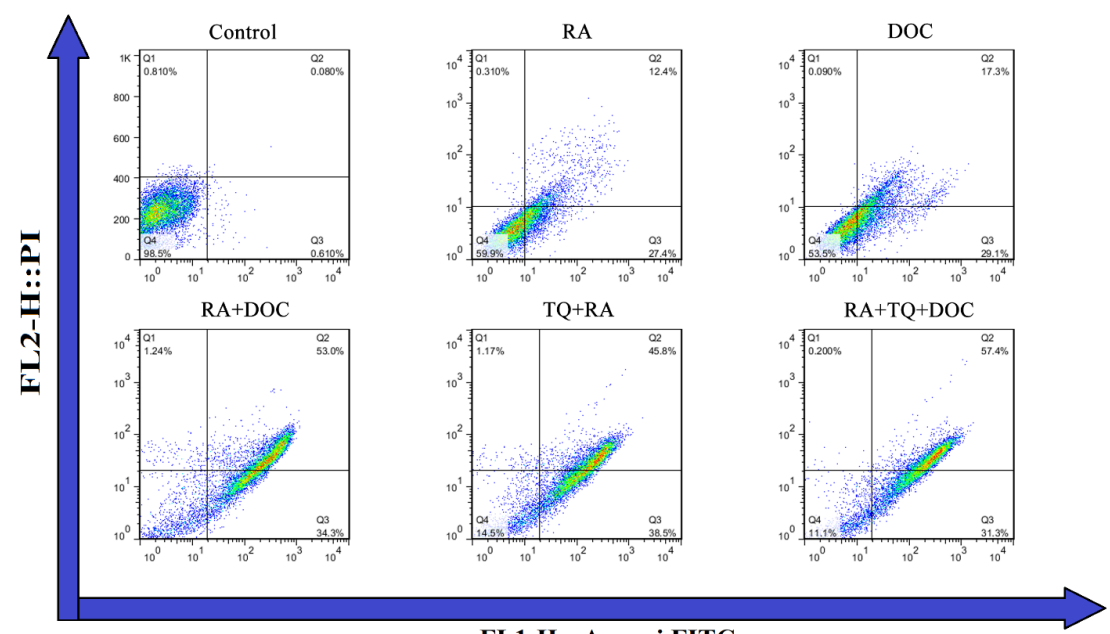

FL1-H:: Annexi FITC

Figure 3. Combinational Effect of Docetaxel, Rosmarinic Acid, and Thymoquinone on the Apoptosis Rate of MDA-MB-231 Cells. Aforementioned cells were exposed under $5 \mathrm{~nm}$ docetaxel only (B), $10 \mu \mathrm{m}$ rosmarinic acid, and thymoquinone alone (C) or a combination $10 \mu \mathrm{m}$ rosmarinic acid and thymoquinone along with $5 \mathrm{~nm}$ docetaxel (D) for $24 \mathrm{~h}$. The apoptotic percentage of MDA-MB-231 cells exposed with docetaxel alone, rosmarinic acid and thymoquinone alone or a combination of docetaxel, rosmarinic acid, and thymoquinone (E).
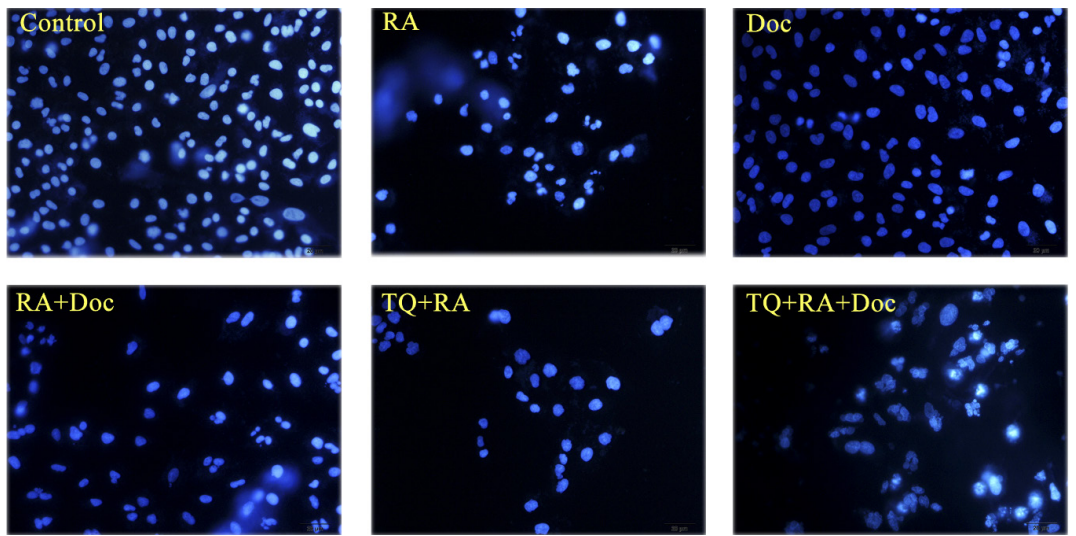

Figure 4. Nuclei Architecture Alteration Following Exposure With Treated With Docetaxel, Rosmarinic Acid and Thymoquinone or a Co-Treatment Condition (A). Amount of apoptotic MDA-MB-231 cells following changed treatment condition of rosmarinic acid, thymoquinone and docetaxel. Cells were treated with distinct concentration of rosmarinic acid $(10 \mu \mathrm{m})$, thymoquinone $(20 \mu \mathrm{m})$ and docetaxel $(2 \mathrm{~nm})$ or combination of rosmarinic acid and thymoquinone with docetaxel for $24 \mathrm{~h}$.

suppression of this pathway may increase the efficiency of cancer chemotherapy. Extensive involvement of the NF- $\mathrm{B}$ pathway in tumors development has recognized them as targets for therapeutic adjuvants (27). Unusual regulation and cross-link of cell-signaling pathways play a significant role in cancer, and blockade of or anomalies in signaling pathways may result in excessive cell propagation, apoptotic resistance, angiogenesis, invasion, and metastasis, leading to expansion and development of cancer (28). NF- $\kappa \mathrm{B}$ is a pivotal signaling pathway implicated in cancer development and progression (29). By managing target genes' expression, such as BCLXL, BCL2, $B C L X S, X I A P$, and VEGF, NF- $\mathrm{BB}$ facilitates cancer-cell proliferation, survival, and angiogenesis (30). The current study verified that rosmarinic acid and thymoquinone, as an inhibitor of NF- $\kappa B$, meaningfully augment the cytotoxic effects of docetaxel in MDA-MB231 cell line holding active
NF- $\kappa$ B. Current data are consistent with previous studies illustrating that the combined chemotherapy rosmarinic acid enhances the anti-neoplastic properties of cisplatin in the human lung cancer cell (31).

To inspect the supposed mechanisms by which rosmarinic acid and thymoquinone enhance docetaxel's cell cytotoxic and apoptotic effect, we carried out in vitro analysis on cell proliferation assay (Figure 1) and apoptosis (Figure 3). Though the exposure of cells with rosmarinic acid, thymoquinone, docetaxel, and a combination of the two or three agents caused enhanced anti-proliferative effect, the number of apoptotic cells was intensely raised following combinatorial treatment versus individual exposure (Figure 2). Current findings were in line with the alterations in the morphology of nuclei attained by the DAPI stain and were related to a perceptible rise in the number of apoptotic nuclei. 


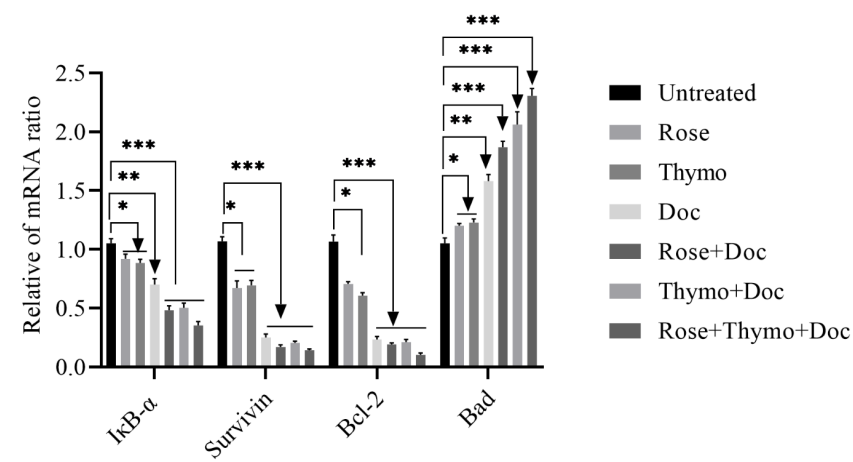

Figure 5. The Effect of Rosmarinic Acid, Thymoquinone, and Docetaxel Separated and Combinatorial Treatment on the Expression Level of Ikb-A, Survivin, Bcl-2 and BAD in MDA-MB-231 Cells. Levels of Ikb-A, survivin, Bcl-2, and BAD mRNA level succeeding incubation with $2 \mathrm{~nm}$ docetaxel, $10 \mu \mathrm{m}$ rosmarinic acid, and $20 \mu \mathrm{m}$ thymoquinone or combination of them for $24 \mathrm{~h}\left({ }^{*} P<0.05,{ }^{* *} P<0.01,{ }^{* * *} P<0.001\right)$.

In the current study, we perceived that the expression levels of downstream NF-kB (Bcl-2 family) protein were augmented in the MDA-MB231. I $\mathrm{B}$ - $\alpha$ can translocate to the nucleus to eliminate NF- $\kappa \mathrm{B}$ from DNA and transport it back to the cytosol to halt transcription (32). In line with these data, the findings of this research designated that the expression of the NF-kB downstream target genes I $\mathrm{B}$ B- $\alpha, \mathrm{Bcl}-2$, and survivin were noticeably declined after incubation with rosmarinic acid, thymoquinone, docetaxel alone, and or their double or triple combination (Figure 5). It has been revealed that high levels of NF-kB activity upregulate many anti-apoptotic factors, including $\mathrm{Bcl} 2$ and Survivin (33).

\section{Conclusions}

In conclusion, the current investigation results established that rosmarinic acid and thymoquinone, as an NF-kB inhibitor, boosted docetaxel-induced cytotoxicity in MDA-MB 231 breast cancer cells. The synergistic antiproliferative effects of rosmarinic acid, thymoquinone, and docetaxel were accompanied by the downregulation of Bcl-2, IкB- $\alpha$, and survivin expression levels. Our finding proposes that applying an NF-kB inhibitor and docetaxel may be a hopeful technique to increase the effectiveness of chemotherapy protocols in patients with breast cancer.

\section{Authors' Contribution}

EAS contributed to formal analysis, methodology, analyzing the results and writing. SAD contributed to conceptualization, investigation, writing and editing, and MG contributed to supervision, methodology, discussion and writing.

\section{Conflict of Interests}

Authors have no conflict of interests.

\section{Ethical Issue}

This study was a part of Ph.D. thesis approved by Islamic Azad University, Tabriz Branch with a Registration No:11455434.

\section{Financial Support}

There was no financial support and grant to report.

\section{Acknowledgments}

Authors would like to thank Dr. Pirouzpanah for giving some valuable materials as gifts.

\section{References}

1. Azamjah N, Soltan-Zadeh Y, Zayeri F. Global trend of breast cancer mortality rate: a 25-year study. Asian Pac J Cancer Prev. 2019;20(7):2015-2020. doi:10.31557/apjcp.2019.20.7.2015

2. Zhang Z, Zhang X, Chen S, et al. Taxane-based chemotherapy and risk of breast cancer-related lymphedema: protocol for a systematic review and meta-analysis. Medicine (Baltimore). 2019;98(30):e16563. doi:10.1097/md.0000000000016563

3. Santa-Maria CA, Gradishar WJ. Adjuvant and neoadjuvant systemic therapies for early-stage breast cancer. In: Bland KI, Copeland EM, Klimberg VS, Gradishar WJ, eds. The Breast. 5th ed. Elsevier; 2018:752-762.e754. doi:10.1016/b978-0-323-35955-9.00055-6

4. Haider K, Rahaman S, Yar MS, Kamal A. Tubulin inhibitors as novel anticancer agents: an overview on patents (2013-2018). Expert Opin Ther Pat. 2019;29(8):623-641. doi:10.1080/13543776.201 9.1648433

5. Galletti E, Magnani M, Renzulli ML, Botta M. Paclitaxel and docetaxel resistance: molecular mechanisms and development of new generation taxanes. ChemMedChem. 2007;2(7):920-942. doi:10.1002/cmdc.200600308

6. Sreekanth CN, Bava SV, Sreekumar E, Anto RJ. Molecular evidences for the chemosensitizing efficacy of liposomal curcumin in paclitaxel chemotherapy in mouse models of cervical cancer. Oncogene. 2011;30(28):3139-3152. doi:10.1038/onc.2011.23

7. Vinod BS, Maliekal TT, Anto RJ. Phytochemicals as chemosensitizers: from molecular mechanism to clinical significance. Antioxid Redox Signal. 2013;18(11):1307-1348. doi:10.1089/ars.2012.4573

8. Yesil-Celiktas O, Sevimli C, Bedir E, Vardar-Sukan F. Inhibitory effects of rosemary extracts, carnosic acid and rosmarinic acid on the growth of various human cancer cell lines. Plant Foods Hum Nutr. 2010;65(2):158-163. doi:10.1007/s11130-010-0166-4

9. Bernardes WA, Lucarini R, Tozatti MG, et al. Antimicrobial activity of Rosmarinus officinalis against oral pathogens: relevance of carnosic acid and carnosol. Chem Biodivers. 2010;7(7):18351840. doi:10.1002/cbdv.200900301

10. Kim DS, Kim HR, Woo ER, Hong ST, Chae HJ, Chae SW. Inhibitory effects of rosmarinic acid on adriamycin-induced apoptosis in H9c2 cardiac muscle cells by inhibiting reactive oxygen species and the activations of c-Jun $\mathrm{N}$-terminal kinase and extracellular signal-regulated kinase. Biochem Pharmacol. 2005;70(7):10661078. doi:10.1016/j.bcp.2005.06.026

11. Randhawa MA, Alghamdi MS. Anticancer activity of Nigella sativa (black seed) - a review. Am J Chin Med. 2011;39(6):1075-1091. doi:10.1142/s0192415x1100941x

12. Imran M, Rauf A, Khan IA, et al. Thymoquinone: a novel strategy to combat cancer: a review. Biomed Pharmacother. 2018;106:390402. doi:10.1016/j.biopha.2018.06.159

13. Bayat Mokhtari R, Homayouni TS, Baluch N, et al. Combination therapy in combating cancer. Oncotarget. 2017;8(23):3802238043. doi:10.18632/oncotarget. 16723 
14. Sabzichi M, Ramezani M, Mohammadian J, et al. The synergistic impact of quinacrine on cell cycle and anti-invasiveness behaviors of doxorubicin in MDA-MB-231 breast cancer cells. Process Biochem. 2019;81:175-181. doi:10.1016/j.procbio.2019.03.007

15. Zhang Y, Li H, Zhang J, et al. The combinatory effects of natural products and chemotherapy drugs and their mechanisms in breast cancer treatment. Phytochem Rev. 2020;19(5):1179-1197. doi:10.1007/s11101-019-09628-w

16. Aggarwal BB, Shishodia S. Molecular targets of dietary agents for prevention and therapy of cancer. Biochem Pharmacol. 2006;71(10):1397-1421. doi:10.1016/j.bcp.2006.02.009

17. Gali-Muhtasib HU, Abou Kheir WG, Kheir LA, Darwiche N, Crooks PA. Molecular pathway for thymoquinone-induced cellcycle arrest and apoptosis in neoplastic keratinocytes. Anticancer Drugs. 2004;15(4):389-399. doi:10.1097/00001813-20040400000012

18. Banerjee S, Kaseb AO, Wang Z, et al. Antitumor activity of gemcitabine and oxaliplatin is augmented by thymoquinone in pancreatic cancer. Cancer Res. 2009;69(13):5575-5583. doi:10.1158/0008-5472.can-08-4235

19. Mohammadian J, Mahmoudi S, Pourmohammad $\mathrm{P}$, et al. Formulation of Stattic as STAT3 inhibitor in nanostructured lipid carriers (NLCs) enhances efficacy of doxorubicin in melanoma cancer cells. Naunyn Schmiedebergs Arch Pharmacol. 2020;393(12):2315-2323. doi:10.1007/s00210-020-01942-x

20. Chou TC. Drug combination studies and their synergy quantification using the Chou-Talalay method. Cancer Res. 2010;70(2):440-446. doi:10.1158/0008-5472.can-09-1947

21. Liu P, Ying Q, Liu $H$, et al. Curcumin enhances anti cancer efficacy of either gemcitabine or docetaxel on pancreatic cancer cells. Oncol Rep. 2020;44(4):1393-1402. doi:10.3892/or.2020.7713

22. Tajmohammadi I, Mohammadian J, Sabzichi M, et al. Identification of Nrf2/STAT3 axis in induction of apoptosis through sub-G (1) cell cycle arrest mechanism in HT-29 colon cancer cells. J Cell Biochem. 2019;120(8):14035-14043. doi:10.1002/jcb.28678

23. Lyseng-Williamson KA, Fenton C. Docetaxel: a review of its use in metastatic breast cancer. Drugs. 2005;65(17):2513-2531. doi:10.2165/00003495-200565170-00007
24. von Minckwitz G. Docetaxel/anthracycline combinations for breast cancer treatment. Expert Opin Pharmacother. 2007;8(4):485-495. doi:10.1517/14656566.8.4.485

25. Gerber B, Freund M, Reimer T. Recurrent breast cancer: treatment strategies for maintaining and prolonging good quality of life. Dtsch Arztebl Int. 2010;107(6):85-91. doi:10.3238/arztebl.2010.0085

26. Cilloni D, Martinelli G, Messa F, Baccarani M, Saglio G. Nuclear factor $\mathrm{kB}$ as a target for new drug development in myeloid malignancies. Haematologica. 2007;92(9):1224-1229. doi:10.3324/haematol.11199

27. Yu LL, Yu HG, Yu JP, Luo HS, Xu XM, Li JH. Nuclear factorkappaB p65 (RelA) transcription factor is constitutively activated in human colorectal carcinoma tissue. World J Gastroenterol. 2004;10(22):3255-3260. doi:10.3748/wjg.v10.i22.3255

28. Zheng J, Yu H, Zhou A, et al. It takes two to tango: coupling of Hippo pathway and redox signaling in biological process. Cell Cycle. 2020;19(21):2760-2775. doi:10.1080/15384101.2020.18 24448

29. Khaki-Khatibi F, Ghorbani M, Sabzichi M, Ramezani F, Mohammadian J. Adjuvant therapy with stattic enriches the anti-proliferative effect of doxorubicin in human ZR-75-1 breast cancer cells via arresting cell cycle and inducing apoptosis. Biomed Pharmacother. 2019;109:1240-1248. doi:10.1016/j. biopha.2018.10.183

30. Baud V, Karin M. Is NF-kappaB a good target for cancer therapy? Hopes and pitfalls. Nat Rev Drug Discov. 2009;8(1):33-40. doi:10.1038/nrd2781

31. Liao XZ, Gao Y, Sun LL, et al. Rosmarinic acid reverses nonsmall cell lung cancer cisplatin resistance by activating the MAPK signaling pathway. Phytother Res. 2020;34(5):1142-1153. doi:10.1002/ptr.6584

32. Bottero V, Imbert V, Frelin C, Formento JL, Peyron JF. Monitoring NFkappa B transactivation potential via real-time PCR quantification of I kappa B-alpha gene expression. Mol Diagn. 2003;7(3-4):187194. doi:10.1007/bf03260037

33. Melisi D, Chiao PJ. NF-kappa B as a target for cance therapy. Expert Opin Ther Targets. 2007;11(2):133-144. doi:10.1517/14728222.11.2.133

Copyright $\odot 2022$ The Author(s); This is an open-access article distributed under the terms of the Creative Commons Attribution License (http://creativecommons.org/licenses/by/4.0), which permits unrestricted use, distribution, and reproduction in any medium, provided the original work is properly cited. 